\title{
Correction to: Evaluation of in vivo anti-inflammatory and anti-angiogenic attributes of methanolic extract of Launaea spinosa
}

\author{
Muhammad Asif ${ }^{1,5}$ (D) Mahrukh ${ }^{1} \cdot$ Malik Saadullah $^{1} \cdot$ Hafiza Sidra Yaseen ${ }^{1} \cdot$ Mohammad Saleem $^{2}$. \\ Hafiz Muhammad Yousaf ${ }^{1} \cdot$ Ikram Ullah Khan $^{1} \cdot$ Maria Yaseen $^{3} \cdot$ Muhammad Usman Shams $^{4}$
}

Published online: 3 August 2020

(c) Springer Nature Switzerland AG 2020

\section{Correction to: \\ Inflammopharmacology volume 28 , pages993- 1008(2020) \\ https://doi.org/10.1007/s10787-020-00687-6}

Unfortunately, a section under the heading "Materials and method" has been published with errors. The complete correct paragraph is given below.

\section{Quantitative chemical characterization by HPLC}

Flavonoids and phenolic contents of Ls.Me were detected through gradient HPLC method. Sample was prepared following reported method and was filtered using syringe filters before injection $(10 \mu \mathrm{L})$ (Sultana et al. 2008). HPLC (LC-10A, Shimadzu, Japan) fitted with Shim-Pack CLCODS column (C-18, Shimadzu, Japan) having dimensions

The original article can be found online at https://doi.org/10.1007/ s10787-020-00687-6.

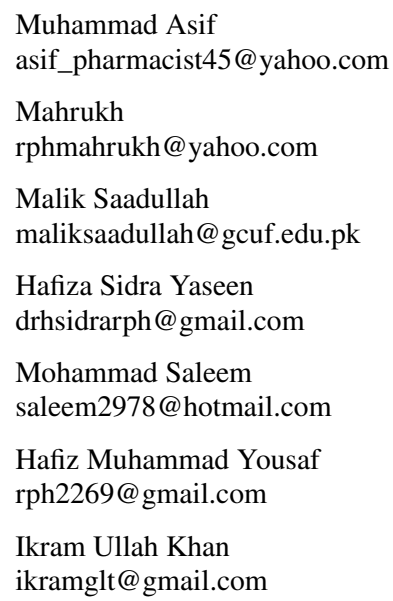

$25 \mathrm{~cm} \times 4.6 \mathrm{~mm}$ internal diameter $\times 5 \mu \mathrm{m}$ particle diameter was used for separation of flavonoids and phenolic compounds at room temperature. Flow rate was set as $1 \mathrm{ml} / \mathrm{min}$ and gradient mobile phase consisting of solvent $\mathrm{A}$ (Water: acetic acid in a 94:6 ratio having $\mathrm{pH} 2.27$ ) and solvent $\mathrm{B}=$ acetonitrile $100 \%, 0-15 \mathrm{~min}=15 \% \mathrm{~B}, 15-30 \mathrm{~min}=45 \%$ B, 30-45 min $=100 \%$ B was used for separation of different compounds. UV-visible detector (SPD-10AV) set at $280 \mathrm{~nm}$ was used for detection of different compounds. Compounds were identified by comparing the retention time of peaks with reference standards.

Publisher's Note Springer Nature remains neutral with regard to jurisdictional claims in published maps and institutional affiliations. 